\title{
Infectious mononucleosis presenting as bilateral acute dacryocystitis
}

\author{
P L Atkinson, A M Ansons, A Patterson
}

\begin{abstract}
A case of infectious mononucleosis presenting as bilateral acute dacryocystitis in a 7-year-old girl is reported. Acute dacryocystitis is uncommon in this age group, and an underlying systemic illness should be suspected particularly when it is bilateral.
\end{abstract}

We report a case of infectious mononucleosis in a child presenting as bilateral acute dacryocystitis.

\section{Case report}

A previously well 7-year-old girl presented with one week's history of malaise, sore throat, and watering eyes. Four days before presentation the eyelids on the left had become swollen, and the eye become red with a purulent discharge. The right eyelids had swollen to a lesser extent. There was no previous history of eye problems; in particular no previous epiphora.

Examination showed bilateral periorbital oedema with bilateral conjunctival injection. Both lacrimal sacs were tender and swollen, more markedly on the left (Figure 1). There was a purulent discharge from the left eye. On applying gentle pressure, mucopurulent material was expressed from the right lacrimal sac.

The patient was pale and lethargic, with a mild pyrexia $\left(37 \cdot 5^{\circ} \mathrm{C}\right)$. Bilateral preauricular and cervical lymphadenopathy and splenomegaly were present. The pharynx was mildly inflamed, with no membrane. The full blood count showed a lymphocytosis (53\%) and atypical mononuclear cells. The Paul-Bunnell test was positive. Streptococcus pneumoniae was grown from the conjunctival discharge.

Empirical treatment with intravenous ampicillin and flucloxacillin was started when the patient presented, and continued for seven days. The dacryocystitis resolved by the fourth day. The epiphora of both eyes had abated and she felt generally well at discharge on the seventh day.

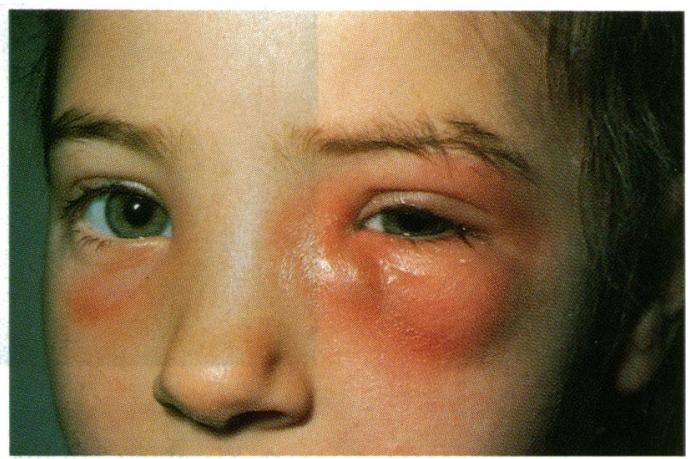

Figure 1 Bilateral dacryocystitis in a girl with infectious mononucleosis.

\section{Discussion}

Infectious mononucleosis can present with ocular involvement, most commonly periorbital oedema, lacrimation, and conjunctivitis. ${ }^{1-3}$ Unilateral acute dacryocystitis is rare. ${ }^{45}$ Infectious mononucleosis presenting as bilateral acute dacryocystitis has not been previously reported.

Acute dacryocystitis is usually seen in adults and infants with pre-existing nasolacrimal duct obstruction and is uncommon in previously asymptomatic children. In infectious mononucleosis the generalised lymphoid hyperplasia, particularly in the nasopharynx, may result in nasolacrimal duct obstruction, with lacrimation. The stagnant secretions in the nasolacrimal sac then become secondarily infected.

Infectious mononucleosis should be considered in previously asymptomatic children and young adults presenting with acute dacryocystitis. In such patients the dacryocystitis can be expected to resolve without permanent nasolacrimal duct obstruction.

1 Sumaya CV, Neerhout RC. Sinusitis and periorbital infections complicating infectious mononucleosis. Am $\mathcal{f}$ Dis Child 1976; 130: 777 .

2 Kouba K, Hlavata E, Karel I. Phlegmonous dacryocystitis and paresis of the soft palate as a rare complication of infectious mononucleosis. Cesk Oftalmol 1970; 26: 181-3.

3 Bessiere E, Agenos B, LeRebeller. Reaction of lacrimal pericystitis during the course of infectious mononucleosis. $\mathcal{F ~ M e d}$ Bordeaux 1962; 139: 73-5.

4 Tanner OR. Ocular manifestations of infectious mononucleosis. Arch Ophthalmol 1954; 51: 229-41.

5 Stevens JE, Bayrd ED, Heck FJ. Infectious mononucleosis. Am ₹ Med 1951; 11: 202-8. 